\title{
Pengaruh People, Process dan Physical Evidence Terhadap Keputusan Mahasiswa Memilih STIBANKS Al Ma'soem (Tahun Akademik 2017/2018)
}

\author{
Faisal Rakhman* \\ Jurusan Perbankan Syariah, STIBANKS Al Ma’soem, Indonesia
}

\begin{abstract}
:
This research aimed to analyze the influence of People, Process and Physical evidence on the students decision choice STIBANKS Al Ma'soem. This research uses quantitative asociative method. The research data was obtained from primary data by distributing questionnaires to students in STIBANKS Al Ma'soem and then processed with IBM SPSS Statistic 23. The results showed that correlation is weak and there are not significant People, Process and Physical evidence on the students decision choice STIBANKS Al Ma'soem. F test results showed that the factors of People, Process and Physical evidence does not significant affect the students decision choice STIBANKS Al Ma'soem. The R-square value obtained amounted to 0.1615, or $16.15 \%$, that meaning simultaneous People, Process and Physical evidence contributes $16.15 \%$ to the effect on the students choise STIBANKS Al Ma'soem, and while the rest $\left(1-R^{2}\right)$ of $83.85 \%$ is the amount of contributions made by other factors not examined. The study reveals that students expect fast response from the officer while giving information to studenst, such as academic information. Students also expect a simply procedure in order their needs, such as to make academic letters. The management of STIBANKS Al Ma'soem must be improve on other factors that can be increase the number of students in the next period, such as service quality and promotion mix.
\end{abstract}

Keywords: people, process, physical evidence, students decision

\section{PENDAHULUAN}

\section{Latar Belakang Masalah}

Pendidikan merupakan kebutuhan bagi setiap manusia. Tuntutan perkembangan jaman dan kemajuan teknologi menuntut dan mendorong manusia untuk terus meningkatkan tingkat pendidikannya. Tingkat pendidikan turut menentukan Indeks Pembangunan Manusia (IPM) dan mempengaruhi kualitas Sumber Daya Manusia (SDM) di suatu daerah dan negara.

\footnotetext{
*Email korespondensi:

Faisal Rakhman

faisalrakhman.mm.almasoem@gmail.com
}

Partisipasi Kasar (APK) Peserta didik di Perguruan Tinggi (PT) tiga tahun terakhir menunjukan peningkatan walaupun tidak signifikan, dimana APK tahun 2015 sebesar 20,89 sedangkan tahun 2016 sebesar 23,44 dan tahun 2017 sebesar 25,00. Hal ini menunjukan bahwa jumlah penduduk yang sedang menempuh pendidikan tinggi masih rendah, apalagi jika dibandingkan dengan negara-negara lain.

Pendidikan Tinggi belum masuk kedalam kategori wajib belajar yang merupakan program dari pemerintah. Hal ini juga diduga salah satu faktor yang 
menyebabkan APK PT masih rendah (Hie, 2013:37-38). Orang tua dan calon peserta didik tentunya masih harus menghitung secara detail dan seksama karena biaya yang dibutuhkan tentunya tidak sedikit. Tidak sedikit yang harus mengurungkan niatan untuk melanjutkan pendidikannya ke PT disebabkan hal tersebut.

Yayasan Al Ma'soem Bandung (YAB) sebagai lembaga penyelenggara pendidikan terus mengembangkan diri dari semula hanya menyelenggarakan pendidikan tingkat Dasar dan Menengah (Dikdasmen) yang dilengkapi dengan boarding school bagi siswa SMP dan SMP, kemudian menyelenggarakan pendidikan tinggi berupa Akademi Manajemen Informatika dan Komputerisasi (AMIK), dan pada tahun 2015 manajemen YAB mendirikan Sekolah Tinggi Ilmu Perbankan Syariah (STIBANKS) Al Ma'soem yang bertujuan untuk menjawab kebutuhan SDM khususnya bagi PT BPRS Al Masoem sebagai unit usaha Ma'soem Group dan juga untuk menyuplai industri Perbankan Syariah (PS) yang terus berkembang.

Al Ma'soem memiliki dua prodi yaitu Perbankan Syariah Program Sarjana (S1) dan Perbankan Syariah Program Diploma (D3) dimana kedua prodi tersebut telah mendapatkan ijin dari Kementrian Agama dan akreditasi dari BAN-PT. STIBANKS Al Ma'soem sebagai Perguruan Tinggi Swasta (PTS) tentunya harus lebih gencar melakukan strategi bauran pemasaran untuk menarik calon mahasiswa agar dapat bersaing dengan sesama PTS dan Perguruan Tinggi Negeri (PTN). Pemasaran PT tidaklah sama dengan pemasaran barang sehingga diperlukan penyesuaian dan strategi tersendiri. Dalam pemasaran jasa pendidikan perlu diperhatikan hal-hal yang berkaitan dengan people, process dan physical evidence (Kotler, 2009:74).
People berkaitan dengan karyawan yang berhubungan langsung dengan calon mahasiswa, dimana tugasnya antara lain memberikan informasi yang menarik dan lengkap kepada calon mahasiswa tersebut (Lupiyoadi \& Hamdani, 2009 : 75). Process merupakan kegiatan yang akan dilalui oleh calon mahasiswa dari mulai mencari informasi, memilih alternatif sampai pada akhirnya membuat keputusan untuk memilih PT yang sesuai (Zethaml \& Bitner, 2000: 20). Sedangkan physical evidence berupa fasilitas serta sarana-prasarana yang mendukung untuk penyelenggaraan pendidikan tinggi juga merupakan daya tarik tersendiri untuk menambah keyakinan calon mahasiswa memilih PT yang memiliki bukti fisik yang memadai (Yazid, 2008: 136).

Manajemen STIBANKS A1 Ma'soem tentunya berupaya sebaik mungkin agar ke-3 aspek bauran pemasaran tersebut dapat dengan optimal dilaksanakan. Lembaga memiliki staff khusus yang bertanggung jawab akan memasarkan lembaga pada pangsa sasaran yang telah ditentukan yaitu khususnya siswa SMA dan sederajat kelas XII, hal ini diperkuat antara lain personal selling, pembuatan MoU antara lembaga dengan beberapa sekolah dalam kerjasama pelaksanaan pelatihan dan uji kompetensi calon lulusan.

Dalam proses menjaring calon mahasiswa selain dilakukan dengan cara konvensional, lembaga juga memanfaatkan kemajuan teknologi informasi antara lain dengan menyediakan website khusus yang dapat diakses untuk memperoleh informasi tentang STIBANKS Al Ma'soem bahkan dapat digunakan sebagai sarana pendaftaran secara online, pemanfaatan sosial media juga diharapkan dapat menjangkau pasar yang lebih luas. Fasilitas gedung, sarana, prasarana yang ada terus dikembangkan agar memadai dalam rangka meningkatkan image dan 
pelayanan kepada mahasiswa dan calon mahasiswa. Gedung tiga tingkat yang dilengkapi dengan berbagai fasilitas seperti ruang kelas ber-AC, mini bank, serta didukung penyedian area wi-fi yang meliputi seluruh lingkungan kampus, tentunya dijadikan unggulan oleh lembaga.

Dalam perkembangannya, jumlah mahasiswa baru yang mendaftar mengalami perubahan, berikut data perubahan jumlah mahasiswa baru STIBANKS Al Ma'soem selama 3 tahun terakhir:

Tabel 1. Jumlah Mahasiswa Baru STIBANKS Al Ma'soem

Tahun Akademik 2015/2016 s.d 2017/2018

\begin{tabular}{|c|c|c|c|}
\hline No. & $\begin{array}{c}\text { Tahun } \\
\text { Akademik }\end{array}$ & Jumlah & Prosentase \\
\hline 1 & $2015 / 2016$ & 128 & - \\
\hline 2 & $2016 / 2017$ & 111 & $-13,3 \%$ \\
\hline 3 & $2017 / 2018$ & 77 & $-30,6 \%$ \\
\hline
\end{tabular}

Sumber : STIBANKS Al Ma'soem

Jumlah mahasiswa baru yang mendaftar ke STIBANKS Al Ma'soem setiap tahunnya mengalami perubahan, dimana pada TA. 2015/2016 terdapat 128 orang dan mengalami penurunan pada TA. 2016/2017 menjadi 111 orang atau sebesar $-13,3 \%$, kemudian mengalami penurunan kembali pada TA. $2017 / 2018$ menjadi 77 orang atau sebesar $-30,6 \%$.

Fenomena yang terjadi tercermin dari penurunan jumlah mahasiswa baru dapat diteliti untuk dicari penyebab dan solusinya, dimana manajemen STIBANKS Al Ma'soem diharapkan lebih memperhatikan keputusan calon mahasiswa atas marketing mix yang telah dilaksanakan.

\section{Identifikasi Masalah}

Berdasarkan uraian latar belakang penelitian, maka penulis menyusun identifikasi masalah yaitu :
1. Bagaimana pengaruh people terhadap keputusan mahasiswa memilih kuliah di STIBANKS Al Ma'soem?

2. Bagaimana pengaruh process terhadap keputusan mahasiswa memilih kuliah di STIBANKS Al Ma'soem?

3. Bagaimana pengaruh physical evidence terhadap keputusan mahasiswa memilih kuliah di STIBANKS Al Ma'soem?

4. Bagaimana pengaruh People, Process dan Physical Evidence secara simultan terhadap keputusan mahasiswa memilih kuliah di STIBANKS Al Ma'soem?

\section{Maksud dan Tujuan Penelitian}

Penulis bermaksud ingin menganalisa pengaruh people, process dan physical evidence terhadap keputusan mahasiswa memilih kuliah di STIBANKS Al Ma'soem. Adapun tujuan penelitian ini yaitu:

1. Untuk mengetahui pengaruh people terhadap keputusan mahasiswa memilih kuliah di STIBANKS Al Ma'soem.

2. Untuk mengetahui pengaruh process terhadap keputusan mahasiswa memilih kuliah di STIBANKS Al Ma'soem.

3. Untuk mengetahui pengaruh physical evidence terhadap keputusan mahasiswa memilih kuliah di STIBANKS Al Ma'soem.

4. Untuk mengetahui pengaruh people, process dan physical evidence secara simultan terhadap keputusan mahasiswa memilih kuliah di STIBANKS Al Ma'soem.

\section{Kerangka Pemikiran}

Berdasarkan identifikasi masalah dimana diduga terdapat pengaruh People, Process dan Physical Evidence secara parsial dan simultan terhadap keputusan mahasiswa memilih kuliah di STIBANKS Al Ma'soem maka dapat digambarkan sebagai kerangka pemikiran penelitian berikut ini: 


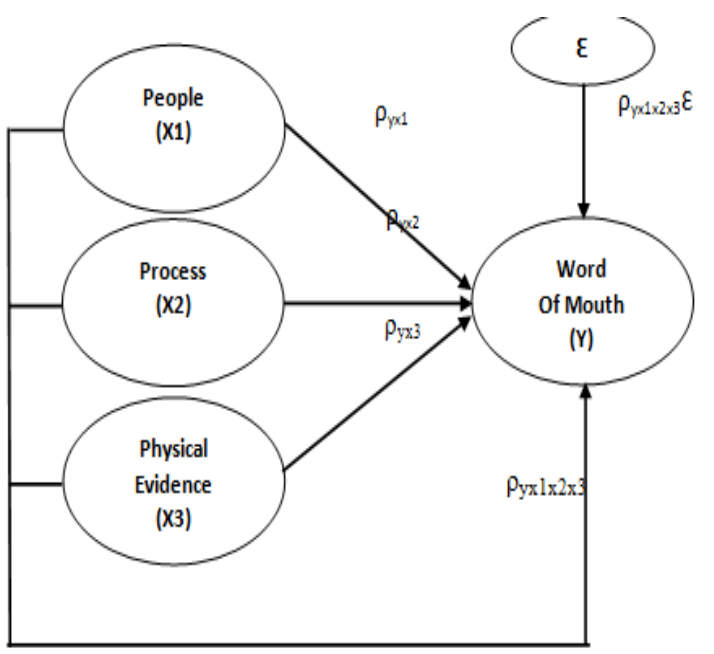

Gambar 1. Kerangka Pemikiran

Sumber: data diolah

Berdasarkan kerangka pemikiran maka hipotesis dalam penelitian ini:

$\mathrm{H}_{1}$ : Terdapat pengaruh people terhadap keputusan mahasiswa memilih kuliah di STIBANKS Al Ma'soem.

$\mathrm{H}_{2}$ : Terdapat pengaruh process terhadap keputusan mahasiswa memilih kuliah di STIBANKS Al Ma'soem.

$\mathrm{H}_{3}$ : Terdapat pengaruh physical evidence terhadap keputusan mahasiswa memilih kuliah di STIBANKS Al Ma'soem.

$\mathrm{H}_{4}$ : Terdapat pengaruh People, Process dan Physical Evidene secara simultan terhadap keputusan mahasiswa memilih kuliah di STIBANKS Al Ma'soem

\section{TINJAUAN PUSTAKA}

\section{People}

Orang (people) adalah semua sumber daya manusia yang berperanan dalam penyajian jasa sehingga dapat mempengaruhi persepsi konsumen (Alma \& Hurriyati, 2008: 165). Sedangkan menurut Lupiyoadi (2006: 75) dalam pemasaran jasa, maka people yang berperan sebagai penyedia jasa dan mempengaruhi kualitas jasa yang diberikan.

Dalam konteks pemasaran jasa perguruan tinggi, people meliputi SDM Badan

Penyelengara PT, Tenaga Pendidik dan Tenaga Kependidikan, dimana SDM tersebut harus memiliki kompetensi yang tinggi karena mereka secara langsung menyampaikan jasa kepada para mahasiswa sehingga tingkat puas atau tidaknya mahasiswa tergantung dari cara penyampaian jasa yang dilakukan (Hurriyati, 2009: 166).

\section{Process}

Proses (process) merupakan gabungan seluruh kegiatan, dimana terdiri dari prosedur, jadwal pekerjaan, mekanisme, aktivitas dan hal-hal rutin, dimana jasa dihasilkan dan disampaikan kepada konsumen (Lupiyoadi \& Hamdani, 2008: 76). Dalam konteks pemasaran jasa pendidikan proses ini dapat diartikan dengan bagaimana proses yang dialami mahasiswa selama dalam pendidikan, misalnya proses belajar-mengajar, proses bimbingan skripsi, proses ujian, proses wisuda, dan lain-lain (Zeithamel \& Bitner, 2008:167).

\section{Physical Evidence}

Bukti fisik (physical evidence) dalam jasa mencakup seluruh lingkungan fisik yang mendukung penyediaan jasa kepada konsumen organisasi selama terjadi (Yazid, 2008: 135). Elemen-elemen dari lingkungan fisik dapat mempengaruhi konsumen melalui atribut-atribut eksterior dan interior. Atributatribut eksterior seperti fasilitas-fasilitas, area parkir, ataupun taman. Atribut-atribut interior seperti design, layout, pencahayaan, peralatan, dan dekorasi. Dalam bisnis jasa bukti fisik merupakan suatu hal yang secara nyata turut mempengaruhi keputusan konsumen untuk membeli dan menggunakan produk jasa yang ditawarkan (Zeithaml \& Bitner dalam Alma \& Hurriyati, 2008:166). Menurut Hurriyati (2009: 167) dalam jasa pendidikan kepada peserta didik, antara lain yang harus diperhatikan oleh BPPT adalah 
Tabel 3. Operasional Variabel

\begin{tabular}{|c|c|c|c|}
\hline Variabel & Dimensi & Indikator & Skala \\
\hline \multirow[t]{2}{*}{$\begin{array}{l}\text { People } \\
\text { (X1) }\end{array}$} & $\begin{array}{l}\text { 1. Service } \\
\text { People }\end{array}$ & $\begin{array}{l}\text { a. Kecepatan Petugas } \\
\text { b. Keramahan Petugas }\end{array}$ & $\begin{array}{l}\text { a. Ordinal } \\
\text { b. Ordinal }\end{array}$ \\
\hline & 2. Customer & $\begin{array}{l}\text { a. Mahasiswa merekomendasi kepada orang lain } \\
\text { b. Mahasiswa puas dengan kualitas jasa yang diperoleh }\end{array}$ & $\begin{array}{l}\text { a. Ordinal } \\
\text { b. Ordinal }\end{array}$ \\
\hline \multirow[t]{2}{*}{$\begin{array}{l}\text { Process } \\
(\mathrm{X} 2)\end{array}$} & 1. Complexity & $\begin{array}{l}\text { a. Kemudahan untuk mengikuti prosedur } \\
\text { b. Pelayanan yang prima }\end{array}$ & $\begin{array}{l}\text { a. Ordinal } \\
\text { b. Ordinal }\end{array}$ \\
\hline & 2. Divergence & $\begin{array}{l}\text { a. Biaya pendaftaran yang rendah } \\
\text { b. Diskon yang diberikan tinggi }\end{array}$ & $\begin{array}{l}\text { a. Ordinal } \\
\text { b. Ordinal }\end{array}$ \\
\hline \multirow{2}{*}{$\begin{array}{l}\text { Physical } \\
\text { Evidence } \\
\text { (X3) }\end{array}$} & $\begin{array}{l}\text { 1. Essential } \\
\text { Evidence }\end{array}$ & $\begin{array}{l}\text { a. Desain dan tata ruang yang menarik } \\
\text { b. Fasilitas kampus yang lengkap }\end{array}$ & $\begin{array}{l}\text { a. Ordinal } \\
\text { b. Ordinal }\end{array}$ \\
\hline & $\begin{array}{l}\text { 2. Peripheral } \\
\text { Evidence }\end{array}$ & $\begin{array}{l}\text { a. Ketersediaan } \mathrm{AC} \\
\text { b. Ketersediaan wi-fi }\end{array}$ & $\begin{array}{l}\text { a. Ordinal } \\
\text { b. Ordinal }\end{array}$ \\
\hline \multirow{5}{*}{$\begin{array}{l}\text { Keputusan } \\
\text { Mahasiswa } \\
\text { (Y) }\end{array}$} & $\begin{array}{l}\text { 1. Pengenalan } \\
\text { Masalah }\end{array}$ & $\begin{array}{l}\text { a. Kebutuhan mahasiswa akan pendidikan tinggi } \\
\text { b. Media promosi yang digunakan }\end{array}$ & $\begin{array}{l}\text { a. Ordinal } \\
\text { b. Ordinal }\end{array}$ \\
\hline & $\begin{array}{l}\text { 2. Pencarian } \\
\text { Informasi } \\
\end{array}$ & $\begin{array}{l}\text { a. Informasi yang bersifat pribadi } \\
\text { b. Informasi dari marketing }\end{array}$ & $\begin{array}{l}\text { a. Ordinal } \\
\text { b. Ordinal }\end{array}$ \\
\hline & $\begin{array}{l}\text { 3. Evaluasi } \\
\text { Alternatif }\end{array}$ & $\begin{array}{l}\text { a. Manfaat dari pendidikan tinggi } \\
\text { b. Jaminan lapangan kerja }\end{array}$ & $\begin{array}{l}\text { a. Ordinal } \\
\text { b. Ordinal }\end{array}$ \\
\hline & $\begin{array}{l}\text { 4. Keputusan } \\
\text { Pembelian }\end{array}$ & $\begin{array}{l}\text { a. Kepopuleran lembaga } \\
\text { b. Gedung yang representatif }\end{array}$ & $\begin{array}{l}\text { a. Ordinal } \\
\text { b. Ordinal }\end{array}$ \\
\hline & $\begin{array}{l}\text { 5. Perilaku } \\
\text { Pasca } \\
\text { Pembelian }\end{array}$ & $\begin{array}{l}\text { a. Kehandalan lulusan } \\
\text { b. Kepuasan setelah menjadi mahasiswa }\end{array}$ & $\begin{array}{l}\text { a. Ordinal } \\
\text { b. Ordinal }\end{array}$ \\
\hline
\end{tabular}

Sumber: data diolah

desain bangunan (segi estetika dan fungsional harus sesuai) begitu pula fasilitas pendukung (sarana prasarana pendidikan, peribadahan, olah raga, dan keamanan).

\section{Keputusan Konsumen}

Kotler \& Keller (2009: 184) menyatakan bahwa "untuk melakukan pembelian produk, secara umum konsumen melalui lima tahap yaitu pengenalan masalah, pencarian informasi, evaluasi alternatif, keputusan pembelian, dan perilaku pascapembelian". Hal ini menjelaskan bahwa proses pembelian dimulai sebelum pembelian sebenarnya dilakukan dan memiliki dampak setelah itu. Keputusan pembelian dapat diartikan suatu sikap konsumen untuk membeli atau menggunakan produk (barang atau jasa) yang telah diyakini dirinya serta kesediaan menanggung resiko yang mungkin terkandung didalamnya.
Keputusan pembelian diambil oleh konsumen merupakan kumpulan dari sejumlah keputusan yang terorganisir (Kotler, 2008: 170).

\section{METODE PENELITIAN Objek Penelitian}

Objek penelitian menurut Sugiyono (2016: 38) yaitu suatu atribut atau sifat dari orang, objek atau kegiatan yang mempunyai variasi tertentu yang ditetapkan oleh peneliti untuk dipelajari dan kemudian ditarik kesimpulannya. Penelitian ini menganalisa pengaruh people, process dan physical evidence terhadap keputusan mahasiswa. sedangkan obyek pada penelitian ini adalah mahasiswa yang memilih kuliah STIBANKS Al Ma'soem pada periode penerimaan calon mahasiswa Tahun Akademik 2017/2018. 


\section{Jenis Penelitian}

Penelitian ini menggunakan metode penelitian kuantitatif yang bersifat asosiatif. Metode penelitian kuantitaif merupakan penelitian positivistik karena berlandaskan pada filsafat positivisme sebagai metode ilmiah yang telah memenuhi kaidah-kaidah ilmiah yaitu rasional dan sistematis dan juga merupakan data penelitian berupa angkaangka dan analisis menggunakan statistik (Sugiyono, 2017: 7). Sedangkan metode penelitian asosiatif menurut Sugiyono (2009: 8) "Metode penelitian asosiatif merupakan penelitian yang dilakukan untuk menggabungkan antara dua variabel atau lebih".

Berdasarkan teori diatas maka penelitian ini merupakan penelitian kuantitatif, data yang diperoleh dari sampel populasi penelitian kemudian dianalisis dengan metode statistik untuk kemudian dipaparkan. Dalam penelitian ini akan menguji kebenaran hipotesis dengan pengumpulan data mengunakan keusioner yang disebarkan pada mahasiswa STIBANKS Al Ma'soem TA. 2017/2018.

\section{Operasionalisasi Variabel}

Penelitian ini terdiri dari tiga variabel independen dimana people $\left(\mathrm{X}_{1}\right)$, process $\left(\mathrm{X}_{2}\right)$ serta physical evidence $\left(\mathrm{X}_{3}\right)$ dan terdapat 1 variabel dependen yaitu keputusan mahasiswa (Y). Adapun pengertian variabel menurut Sugiyono (2017: 2) bahwa variabel merupakan segala sesuatu yang berbentuk apa saja yang ditetapkan oleh peneliti untuk dipelajari sehingga diperoleh informasi tentang hal tersebut, kemudian ditarik kesimpulannya. Selanjutnya variabel independen dan dependen diukur menggunakan skala Likert. Menurut Sugiyono (2014: 93) Skala Likert yaitu digunakan untuk mengukur sikap, pendapat dan persepsi seseorang atau kelompok orang tentang fenomena sosial.

Tabel 2. Skala Likert Analisis Kuantitatif

\begin{tabular}{|c|l|c|}
\hline No & \multicolumn{1}{|c|}{ Keterangan } & Skor \\
\hline 1. & Setuju/selalu/sangat positif & 5 \\
\hline 2. & Setuju/sering/positif & 4 \\
\hline 3. & $\begin{array}{l}\text { Ragu-ragu/kadang- } \\
\text { kadang/netral }\end{array}$ & 3 \\
\hline 4. & $\begin{array}{l}\text { Tidak setuju/hampir tidak } \\
\text { pernah/negatif }\end{array}$ & 2 \\
\hline 5. & $\begin{array}{l}\text { Sangat tidak setuju/tidak } \\
\text { pernah }\end{array}$ & 1 \\
\hline
\end{tabular}

Sumber: Sugiyono (2014: 94)

\section{Populasi}

Definisi populasi menurut Sugiyono (2017: 61) merupakan wilayah generalisasi yang terdiri atas obyek/subyek yang mempunyai kuantitas dan karakteristik tertentu yang ditetapkan oleh peneliti untuk dipelajari dan kemudian ditarik kesimpulannya. Dalam penelitian ini yang menjadi populasi adalah seluruh mahasiswa STIBANKS Al Ma'soem TA. 2017/2018 yang berjumlah 77 orang.

\section{Sampel}

Pengertian sampel menurut Sugiyono (2017: 62) adalah bagian dari jumlah dan karakteristik yang dimiliki oleh populasi. Penentuan jumlah sampel atau responden menggunakan perhitungan mengacu pada rumus Slovin:

$$
n=\frac{N}{1+N e^{2}}
$$

Keterangan :

$n$ : jumlah sampel

$\mathrm{N}$ : jumlah populasi

$\mathrm{e}$ : batas toleransi kesalahan

Berikut perhitungan jumlah mahasiswa STIBANKS Al Ma'soem TA. 2017/2018 yang akan dijadikan sampel, yaitu : 


$$
\begin{aligned}
n & =N /\left(1+N e^{2}\right) \\
& =77 /\left(1+77 \times 0,1^{2}\right) \\
& =43,50 \approx 44
\end{aligned}
$$

Berdasarkan hasil perhitungan maka sampel dari penelitian ini sebanyak 44 mahasiswa STIBANKS Al Ma'soem TA. 2017/2018.

\section{Uji Validitas}

Menurut Misbahuddin \& Hasan (2014) Uji validitas adalah suatu ukuran yang menunjukkan tingkat kesahihan suatu instrumen. Instrumen sahih atau valid, berarti memiliki validitas tinggi. Sebuah instrumen dikatakan sahih apabila mampu mengukur apa yang diinginkan atau mengungkap data dari variabel yang diteliti secara tepat. Uji validitas diperoleh dari skor-skor kuisioner yang dihitung dengan membandingkan $r_{\text {tabel }}$ product moment dengan menggunakan bantuan aplikasi IBM SPSS Statistics 23 untuk memperoleh hasil yang terarah yaitu dengan memperhatikan angka pada Corrected Item Total Correlations yang merupakan korelasi antara skor item dengan skor total item.

Rumus uji validitas adalah sebagai berikut :

\section{Validitas pada $\mathrm{r}$ tabel $=\mathrm{N}-2$}

$\mathrm{N}=$ Sampel yang didapat

Kriteria pengujian validitas penelitian adalah sebagai berikut:

1. Jika $r_{\text {hitung }}>r_{\text {tabel }}$ maka pengujian tersebut valid

2. Jika $r_{\text {hitung }}<r_{\text {tabel }}$ maka pengujian tersebut tidak valid

Jika $r_{\text {hitung }}>r_{\text {tabel }}$ maka pernyataan tersebut valid. Dalam hal ini $r_{\text {tabel }}$ dengan $\mathrm{N}=44$, dikurangi 2 menjadi 42 sampel adalah 0,251 .

\section{Uji Reliabilitas}

Definisi uji reliabilitas menurut Sugiyono (2016: 183) yaitu uji yang digunakan untuk menunjukkan bahwa sesuatu instrumen cukup dapat dipercaya untuk digunakan sebagai alat pengumpul data karena instrumen tersebut sudah baik. Uji Reliabilitas adalah analisis yang banyak digunakan untuk mengetahui konsistensi alat ukur yang menggunakan skala, kuesioner. Menggunakan teknik Cronbach alpha dengan bantuan program IBM SPSS Statistics 23. Berikut tabel pengukuran tingkat reliabilitas yang menjadi acuan reliabel atau tidaknya suatu pernyataan:

Tabel 4. Tingkat Reliabilitas

\begin{tabular}{|c|c|c|}
\hline No. & Alpha & Keterangan \\
\hline 1 & $<0,50$ & Reliabilitas Rendah \\
\hline 2 & $0,50-0,70$ & Reliabilitas Moderat \\
\hline 3 & $0,70-0,90$ & Reliabilitas Tinggi \\
\hline 4 & $>0,90$ & Reliabilitas Sempurna \\
\hline
\end{tabular}

Sumber: Sugiyono (2016)

\section{Analisis Korelasi Berganda}

Pengertian analisis korelasi berganda menurut Sugiyono (2017: 230) yaitu merupakan angka yang menunjukkan arah dan kuatnya hubungan antara dua variabel independen (atau lebih) secara bersama-sama dengan satu variabel dependen. Adapun rumusnya sebagai berikut:

$$
R y(1,2,3)=\frac{b_{1} \sum X_{1} Y+b_{2} \sum X_{2} Y+b_{3} \sum X_{3} Y}{\sum Y^{2}}
$$

Keterangan :

$\sum X_{1} \quad$ = jumlah data $X_{1}$

$\sum Y=$ jumlah dari $\mathrm{Y}$

$\sum X_{1} Y=$ Jumlah dari $\mathrm{X}_{1}$ dan $\mathrm{Y}$

$\mathrm{b} 1, \mathrm{~b} 2, \mathrm{~b} 3=$ Koefisien regresi masing-masing variabel

Adapun hasil dari pengujian koefisien korelasi tersebut seberapa kuat hubungan antara hubungan $\mathrm{X}_{1}, \mathrm{X}_{2}, \mathrm{X}_{3}$ terhadap $\mathrm{Y}$, 
terdapat pada tabel interpretasi koefisien korelasi:

Tabel 5. Interpretasi Koefisien Korelasi

\begin{tabular}{|c|c|l|}
\hline No & Interval Koefisien & $\begin{array}{c}\text { Tingkat } \\
\text { Hubungan }\end{array}$ \\
\hline 1. & $0,00-0,199$ & Sangat Rendah \\
\hline 2. & $0,20-0,399$ & Rendah \\
\hline 3. & $0,40-0,599$ & Sedang \\
\hline 4. & $0,60-0,799$ & Kuat \\
\hline 5. & $0,80-1,000$ & Sangat Kuat \\
\hline
\end{tabular}

Sumber: Sugiyono (2014: 184)

\section{Analisis Regresi Berganda}

Menurut Sugiyono (2017: 275) analisis regresi berganda digunakan oleh peneliti, bila peneliti bermaksud meramalkan bagaimana keadaan (naik turunnya) variabel dependen (kriterium), bila dua atau lebih variabel independen sebagai faktor predikator dimanipulasi (dinaik turunkan nilainya. Adapun persamaan dari regresi berganda untuk tiga predikator, yaitu sebagai berikut :

$$
Y=a+b_{1} X_{1}+b_{2} X_{2}+b_{3} X_{3}
$$

Penelitian dilakukan untuk mengetahui persamaan regresi pengaruh people, process dan physical evidence secara bersama-sama terhadap kuputusan mahasiswa memilih STIBANKS Al Ma'soem. Dimana :

$\mathrm{Y}=$ Variabel Dependen (Keputusan Mahasiswa)

$\mathrm{a}=$ Koefisien Regresi (Konstanta)

$\mathrm{b}_{1}=$ Koefisien Regresi people

$\mathrm{b}_{2}=$ Koefisien Regresi process

$\mathrm{b}_{3}=$ Koefisien Regresi physical evidence

$\mathrm{X}_{1}=$ People

$\mathrm{X}_{2}=$ Process

$\mathrm{X}_{3}=$ Physical Evidence

\section{Analisis Koefisien Determinasi Berganda}

Menurut Kazmier (2004: 123) koefisien determinasi berganda mengindikasikan proporsi varians dalam variabel dependen yang secara statistik bertanggung jawab dengan diketahuinya nilai dua variabel independen (atau lebih). Berikut ini rumus untuk menghitung Koefisien determinasi berganda:

$$
\mathrm{R}_{\mathrm{y}}{ }^{2 \cdot 12}=\frac{1-\mathrm{S}_{\mathrm{y}}{ }^{2} \cdot 12}{\mathrm{~S}_{\mathrm{y}}{ }^{2}}
$$

\section{Rancangan Uji t}

Menurut Kazmier (2004: 120) Uji t digunakan untuk menentukan apakah koefisien regresi parsial untuk setiap variabel independen mencerminkan kontribusi yang signifikan terhadap model keseluruhan. Kaidah pengambilan keputusan dalam uji $\mathrm{t}$ dengan menggunakan IBM SPSS Statistics 23 dengan tingkat signifikasi yang ditetapkan adalah $10 \%$ :

1. Jika nilai signifikansi > 0,1 , maka Ho diterima dan Ha ditolak, atau variabel bebas tidak dapat menjelaskan variabel terikat atau tidak ada pengaruh antara variabel yang diuji.

2. Jika nilai signifikansi $<0,1$, maka Ho ditolak dan Ha diterima, atau variabel bebas dapat menjelaskan variabel terikat atau ada pengaruh antara variabel yang diuji.

\section{Rancangan Uji F}

Uji $F$ digunakan untuk menguji signifikansi model keseluruhan, analisis varians digunakan dalam analisis regresi untuk menguji signifikansi model keseluruhan, kebalikan dengan pengukuran signifikansi variabel independen individual dengan pemakaian uji t (Leonard Kazmier, 2004: 120). Maka untuk kasus tiga variabel independen, hipotesis nol dalam hubungannya dengan uji $F$ adalah $H_{0}: \beta_{1}=\beta_{2}$ $=\beta_{3}=0$.

Kriteria pengambilan keputusan dalam uji $\mathrm{F}$ dengan menggunakan IBM SPSS Statistics 23 adalah: 
1. Jika nilai signifikansi > 0,1 , maka Ho diterima dan $\mathrm{H}_{\mathrm{a}}$ ditolak, atau variabel bebas dari model regresi linier tidak mampu menjelaskan variabel terikat.

2. Jika nilai signifikansi $<0,1$, maka Ho ditolak dan $\mathrm{H}_{\mathrm{a}}$ diterima, atau variabel bebas dari model regresi linier mampu menjelaskan variabel terikat.

\section{Koefisien Determinasi $\left(\mathbf{R}^{\mathbf{2}}\right)$}

Koefisien determinasi $\left(\mathrm{R}^{2}\right)$ pada intinya bertujuan untuk mengukur seberapa jauh kemampuan model dalam menerangkan variasi variabel dependen. Nilai koefisien determinasi adalah antara nol dan satu.

\section{HASIL DAN PEMBAHASAN Profil Responden}

Responden dalam penelitian ini adalah mahasiswa STIBANKS Al Ma'soem TA 2017/2018 sebanyak 44 orang. Profil responden dalam penelitian ini, maka dilakukan pengelompokan responden berdasarkan: jenis kelamin, usia, program studi dan kelas perkuliahan.

1. Jenis Kelamin: Laki-laki $=21 \%$ dan Wanita $=79 \%$.

2. Usia: kurang dari 18 tahun $=7 \%, 18$ s.d 20 tahun $=78 \%$, lebih dari 20 tahun $=$ $15 \%$

3. Program Studi: Program sarjana $(\mathrm{S} 1)=$ $89 \%$ dan Program diploma (D3) $=11 \%$.

4. Kelas Perkuliahan: Kelas pagi $=61 \%$ dan Kelas sore $=39 \%$.

\section{Uji Validitas}

Penulis menguji tingkat validitas kuesioner yang disebarkan kepada 44 responden kemudian hasilnya diolah dengan IBM SPSS Statistics 23. Dimana terdapat responden sebanyak 44, maka nilai $r$ tabel dapat diperoleh melalui $\mathrm{df}=\mathrm{n}-2$. Jadi $\mathrm{df}=44$ $2=42$, maka $r$ tabel sebesar 0,251, maka menghasilkan data masing-masing variabel:

1. Uji Validitas Variabel People $\left(\mathrm{X}_{1}\right)$, seluruh pernyataan $X_{1}$ sebanyak 4 pernyataan dinyatakan valid karena berdasarkan pengolahan data $\mathrm{r}$ hitung > $r$ tabel.

2. Uji Validitas Variabel Process $\left(X_{2}\right)$, seluruh pernyataan $\mathrm{X}_{2}$ sebanyak 4 pernyataan dinyatakan valid karena berdasarkan pengolahan data $\mathrm{r}$ hitung > $r$ tabel.

3. Uji Validitas Variabel Physical Evidence $\left(\mathrm{X}_{3}\right)$, seluruh pernyataan $\mathrm{X}_{3}$ sebanyak 4 pernyataan dinyatakan valid karena berdasarkan pengolahan data $r$ hitung > $r$ tabel.

4. Uji Validitas Variabel Keputusan mahasiswa (Y), seluruh pernyataan $\mathrm{Y}$ sebanyak 10 pernyataan dinyatakan valid karena berdasarkan pengolahan data $\mathrm{r}$ hitung $>\mathrm{r}$ tabel.

\section{Uji Reliabilitas}

\section{Uji Reliabilitas Variabel People $\left(X_{I}\right)$}

Hasil pengolahan uji reliabilitas $X_{1}$ sebagai berikut:

\section{Tabel 6. Hasil Uji Reliabilias People

\begin{tabular}{|l|l|}
\hline Cronbach's Alpha & N of Items \\
\hline 0,744 & 4 \\
\hline
\end{tabular}

Sumber : data diolah

Reliabilitas suatu konstruk variabel dikatakan baik jika memiliki nilai cronbach's alpha lebih besar dari 0,60. Berdasarkan tabel diatas dapat dilihat bahwa cronbach's alpha 0,744 lebih besar dari 0,60. Dapat disimpulkan bahwa pertanyaan kuesioner untuk variabel People $\left(\mathrm{X}_{1}\right)$ adalah reliabel.

\section{Uji Reliabilitas Variabel Process $\left(\mathrm{X}_{2}\right)$}

Hasil pengolahan uji reliabilitas $X_{2}$ sebagai berikut: 
Tabel 6. Hasil Uji Reliabilias Process

\begin{tabular}{|l|l|}
\hline Cronbach's Alpha & N of Items \\
\hline 0,781 & 4 \\
\hline
\end{tabular}

Sumber : data diolah

Reliabilitas suatu konstruk variabel dikatakan baik jika memiliki nilai cronbach's alpha lebih besar dari 0,60. Berdasarkan tabel diatas dapat dilihat bahwa cronbach's alpha 0,781 lebih besar dari 0,60. Dapat disimpulkan bahwa pertanyaan kuesioner untuk variabel Process $\left(\mathrm{X}_{2}\right)$ adalah reliabel.

\section{Uji Reliabilitas Variabel Physical Evidence} $\left(X_{3}\right)$

Hasil pengolahan uji reliabilitas $\mathrm{X}_{3}$ sebagai berikut:

Tabel 8. Hasil Uji Reliabilias Physical Evidence

\begin{tabular}{|l|l|}
\hline Cronbach's Alpha & N of Items \\
\hline 823 & 4 \\
\hline
\end{tabular}

Sumber : data diolah

Reliabilitas suatu konstruk variabel dikatakan baik jika memiliki nilai cronbach's alpha lebih besar dari 0,60. Berdasarkan tabel diatas dapat dilihat bahwa cronbach's alpha 0,823 lebih besar dari 0,60. Dapat disimpulkan bahwa pertanyaan kuesioner untuk variabel Physical evidence $\left(\mathrm{X}_{3}\right)$ adalah reliabel.

\section{Uji Reliabilitas Variabel Keputusan Mahasiswa (Y)}

Hasil pengolahan uji reliabilitas $\mathrm{Y}$ sebagai berikut:

\section{Tabel 9. Hasil Uji Reliabilias Keputusan} Mahasiswa

\begin{tabular}{|l|l|}
\hline Cronbach's Alpha & $\mathrm{N}$ of Items \\
\hline 0.675 & 10 \\
\hline
\end{tabular}

Sumber : data diolah

Reliabilitas suatu konstruk variabel dikatakan baik jika memiliki nilai cronbach's alpha lebih besar dari 0,60. Berdasarkan tabel diatas dapat dilihat bahwa cronbach's alpha 0,675 lebih besar dari 0,60. Dapat disimpulkan bahwa pertanyaan kuesioner untuk variabel keputusan mahasiswa (Y) adalah reliabel.

\section{Pengujian Koefisien Korelasi Spearman's}

Angka koefesien korelasi Spearman antara variabel people terhadap keputusan mahasiswa sebesar 0,186 dengan tingkat signifikansi 0,000 pada tingkat 0,01 , hal ini berartinya berasarkan perhitungan statistik antara kedua variabel tersebut berkorelasi positif dengan tingkat hubungan sangat rendah.

Sedangkan angka koefesien korelasi Spearman antara variabel process terhadap keputusan mahasiswa sebesar 0,154 dengan tingkat signifikansi 0,000 pada tingkat 0,01 hal ini berartinya berasarkan perhitungan statistik antara kedua variabel tersebut berkorelasi positif dengan tingkat hubungan sangat rendah.

Adapun angka koefesien korelasi Spearman antara variabel physical evidence terhadap keputusan mahasiswa sebesar 0,201 dengan tingkat signifikansi 0,000 pada tingkat 0,01 hal ini berartinya berasarkan perhitungan statistik antara kedua variabel tersebut berkorelasi positif dengan tingkat hubungan rendah.

\section{Pengujian Hipotesis}

Angka koefesien korelasi Spearman antara variabel People terhadap keputusan mahasiswa memiliki tingkat signifikasi sebesar 0,145 . Hipotesis variabel $\mathrm{X}_{1}$ terhadap $\mathrm{Y}$ :

$\mathrm{Ho}_{1}$ : People $\left(\mathrm{X}_{1}\right)$ tidak berpengaruh signifikan terhadap Keputusan mahasiswa (Y).

$\mathrm{Ha}_{1}$ : People $\left(\mathrm{X}_{1}\right)$ berpengaruh signifikan terhadap Keputusan mahasiswa (Y).

Karena nilai Sig dari tabel diatas adalah 0,145 (>0,10) maka Ho diterima dan Ha ditolak, hal ini berarti People (X1) tidak 
berpengaruh signifikan terhadap Keputusan mahasiswa (Y).

Angka koefesien korelasi Spearman antara variabel Process terhadap Keputusan mahasiswa memiliki tingkat signifikasi sebesar 0,112 . Hipotesis variabel $\mathrm{X}_{2}$ terhadap $\mathrm{Y}$ :

$\mathrm{Ho}_{2}$ : Process $\left(\mathrm{X}_{2}\right)$ tidak berpengaruh signifikan terhadap Keputusan mahasiswa (Y).

$\mathrm{Ha}_{2}$ : Process $\left(\mathrm{X}_{2}\right)$ berpengaruh signifikan terhadap Keputusan mahasiswa (Y).

Karena nilai Sig dari tabel diatas adalah $0,112(>0,10)$ maka Ho diterima dan $\mathrm{Ha}$ ditolak, hal ini berarti Process $\left(\mathrm{X}_{2}\right)$ tidak berpengaruh signifikan terhadap Keputusan mahasiswa (Y).

Angka koefesien korelasi Spearman antara variabel Physical evidence terhadap Keputusan mahasiswa memiliki tingkat signifikasi sebesar 0,093. Hipotesis variabel $\mathrm{X}_{3}$ terhadap Y:

Ho3: Physical evidence $\left(\mathrm{X}_{3}\right)$ tidak berpengaruh signifikan terhadap keputusan mahasiswa (Y).

$\mathrm{Ha}_{3}: \quad$ Physical evidence $\left(\mathrm{X}_{3}\right)$ berpengaruh signifikan terhadap keputusan mahasiswa (Y).

Karena nilai Sig dari tabel diatas adalah $0,093 \quad(<0,10)$ maka Ho ditolak dan $\mathrm{Ha}$ diterima, hal ini berarti Physical evidence $\left(\mathrm{X}_{3}\right)$ berpengaruh secara signifikan terhadap keputusan mahasiswa (Y).

\section{Uji Hipotesis Simultan (Uji-F)}

Rumusan hipotesis simultan yang akan diuji adalah:

Ho : People $\left(\mathrm{X}_{1}\right)$, Process $\left(\mathrm{X}_{2}\right)$ dan Physical evidence $\left(\mathrm{X}_{3}\right)$ secara bersama-sama tidak berpengaruh signifikan terhadap Keputusan mahasiswa(Y).

Ha : People $\left(\mathrm{X}_{1}\right)$, Process $\left(\mathrm{X}_{2}\right)$ dan Physical evidence $\left(\mathrm{X}_{3}\right)$ secara bersama-sama berpengaruh signifikan terhadap Keputusan mahasiswa(Y).
Diperoleh nilai F-hitung sebesar 5,519 dengan $\mathrm{p}$-value (sig) 0,01 . Dengan $\alpha=0,1$ serta derajat kebebasan df $1=\mathrm{k}-1=4-1=$ 3 dan df $2=n-k=44-3=41$, maka dapat dilihat F-tabel 3,03. Dikarenakan F-hitung > F-tabel $(5,519>3,03)$, maka Ho ditolak dan Ha diterima, artinya People $\left(\mathrm{X}_{1}\right)$, Process $\left(\mathrm{X}_{2}\right)$ dan Physical evidence $\left(\mathrm{X}_{3}\right)$ secara bersama-sama berpengaruh signifikan terhadap keputusan mahasiswa (Y).

\section{Koefisien Determinasi}

Koefisien determinasi untuk mengetahui besarnya pengaruh atau kontribusi variabel people, process dan physical evidence terhadap keputusan mahasiswa. Rumus koefisien determinasi menurut (Sugiyono, 2012: 257) sebagai berikut :

\section{$\mathbf{K d}=\mathbf{R}^{2} \times 100 \%$}

Keterangan:

Kd : Koefisien determinasi

$\mathrm{R}^{2}$ : Koefisien korelasi yang dikuadratkan

Uji koefisien determinasi diperoleh nilai $\mathrm{R}$ square yang diperoleh adalah sebesar 0,1615 atau $16,15 \%$, artinya secara simultan People, Process dan Physical evidence memberikan kontribusi pengaruh sebesar $16,15 \%$ terhadap Keputusan mahasiswa memilih STIBANKS Al Ma'soem, sedangkan sisanya $\left(1-\mathrm{R}^{2}\right)$ sebesar $83,85 \%$ merupakan besarnya kontribusi yang diberikan oleh faktor lain, seperti kualitas pelayanan dan bauran promosi.

Untuk mengetahui kontribusi pengaruh secara parsial, dapat diketahui dari hasil perkalian antara nilai beta yang merupakan koefisien regresi terstandarkan dengan zero-order yang merupakan korelasi parsial. Perhitungan koefisien determinasi parsial disajikan pada tabel: 
Tabel 10. Koefisien Determinasi Parsial

\begin{tabular}{|c|c|c|c|}
\hline \multirow[t]{2}{*}{ Model } & $\begin{array}{l}\text { Standardized } \\
\text { Coefficients }\end{array}$ & Correlations & $\begin{array}{c}\text { Partial } \\
\text { Coeficient of } \\
\text { Determination }\end{array}$ \\
\hline & Beta & Zero-order & \\
\hline $1 \mid \begin{array}{l}\text { (Cons } \\
\operatorname{tant})\end{array}$ & & & \\
\hline $\mathrm{X} 1$ & .134 & .267 & $5,37 \%$ \\
\hline $\begin{array}{l}\mathrm{X} 2 \\
\mathrm{X} 3\end{array}$ & $\begin{array}{l}.220 \\
.201\end{array}$ & $\begin{array}{l}.301 \\
.215\end{array}$ & $\begin{array}{l}4,86 \% \\
5,92 \%\end{array}$ \\
\hline
\end{tabular}

Sumber : Data diolah

Dapat dijelaskan bahwa people mempengaruhi keputusan mahasiswa sebesar $5,37 \%$, process mempengaruhi keputusan mahasiswa sebesar $4,86 \%$ dan physical evidence mempengaruhi keputusan mahasiswa sebesar 5,92\%, sehingga total pengaruh yang diberikan oleh ketiga variabel sebesar $16,15 \%$.

\section{PENUTUP}

\section{Kesimpulan}

Berdasarkan hasil penelitian dan analisis pengaruh people, process dan physical evidence terhadap keputusan mahasiswa memilih STIBANKS Al Ma'soem dapat disimpulkan:

1. Terdapat pengaruh namun lemah dan tidak signifikan people terhadap keputusan mahasiswa memilih STIBANKS Al Ma'soem. Hal ini tercermin dari hasil uji koefisien korelasi sebesar 0,186.

2. Terdapat pengaruh namun lemah dan tidak signifikan process terhadap keputusan mahasiswa memilih STIBANKS Al Ma'soem. Hal ini tercermin dari hasil uji koefisien korelasi sebesar 0,154.

3. Terdapat pengaruh namun lemah dan tidak signifikan physical evidence terhadap keputusan mahasiswa memilih STIBANKS Al Ma'soem. Hal ini tercermin dari hasil uji koefisien korelasi sebesar 0,201.

4. Secara simultan terdapat tidak terdapat pengaruh yang signifikan antara people, process dan physical evidence terhadap keputusan mahasiswa memilih STIBANKS Al Ma'soem. Hal tersebut didasarkan pada hasil uji $F$ yang menunjukkan bahwa nilai Fhitung sebesar 0,18 lebih besar dari tingkat signifikasi alpha sebesar 0,10, maka Ho diterima dan Ha ditolak, yang berarti people, process dan physical evidence secara simultan tidak berpengaruh secara signifikan terhadap keputusan mahasiswa.

\section{Saran}

Adapun saran dari penulis dalam rangka peningkatan kualitas bauran pemasaran (people, process dan physical evidence) sebagai berikut:

1. Diharapkan untuk meningkatkan kecepatan petugas dalam memberikan pelayanan kepada mahasiswa, seperti dalam hal penyampaian informasi akademik khususnya berkaitan dengan informasi nilai. Hal ini dapat ditanggulangi dengan optimalisasi sistem informasi akademik (SIAK) yang sudah ada, antaralain dengan menambah unit komputer SIAK yang dapat digunakan oleh mahasiswa.

2. Diharapkan prosedur yang ada diperingkas agar dalam pemenuhan kebutuhan mahasiswa seperti dalam hal pembuatan surat keterangan lebih cepat selesai. Hal ini dapat diminimalisir dengan sosialisasi terus menerus dan optimalisasi sistem informasi mahasiswa yang sudah ada agar mahasiswa mengetahui dan dapat menggunakannya secara mudah. 
3. Diharapkan fasilitas yang sudah cukup lengkap secara bertahap terus disempurnakan dan ditingkatkan lagi agar dapat menciptakan suasana kampus yang nyaman dan kondusif untuk proses perkuliahan.

\section{DAFTAR PUSTAKA}

Alma, B., \& Hurriyati, R. (2008). Manajemen Coorporate dan Pemasaran Jasa Pendidikan. Bandung: Alfabeta.

Hie, B. P. (2013). Revolusi Sistem Pendidikan Nasional. Jakarta: Gramedia Pustaka Utama.

Hurriyati, R. (2009). Bauran Pemasaran dan Loyalitas Konsumen. Bandung: Alfabeta.

Hurriyati, R. (2009). Bauran Pemasaran dan Loyalitas Konsumen Fokus Pada Konsumen dan Kartu Kredit Perbankan. Bandung: Alfabeta.

Kazmier, L. (2004). Statistik Untuk Bisnis. Jakarta: Erlangga.

Kotler, P. (2009). Marketing 9th Edition. Jakarta: PT Prehallindo.

Kotler, P., \& Keller, K. L. (2009). Manajemen Pemasaran 2 Edisi Keduabelas. Jakarta: PT. Indeks.
Kotler, P., \& Keller, K. L. (2008). Manajemen Pemasaran. Jakarta: Erlangga.

Kotler, P., \& Keller, K. L. (2008). Manajemen Pemasaran Edisi Keduabelas. Jakarta: PT. Indeks.

Lupiyoadi, H. (2008). Manajemen Pemasaran Jasa. Jakarta: Salemba Empat.

Lupiyoadi, H. (2009). Manajemen Pemasaran Jasa. Jakarta: Salemba Empat.

Misbahuddin, \& Hasan, I. (2014). Analisis Data Penelitian dengan Statistik. Jakarta: Bumi Aksara.

Sugiyono. (2016). Metode Penelitian Kuantitatif, Kualitatif dan $R \& D$. Bandung: Alfabeta.

Sugiyono. (2017) Statistika Untuk Penelitian. Bandung: Alfabeta.

Yazid. (2008). Pemasaran Jasa Edisi Kedua. Jogjakarta: Ekonisia Kampus Fakultas Ekonomi UII.

Zeithaml, V. A., \& Bitner, M. J. (2000). Service Marketing. Singapore: Mc Graw-Hill Companies Inc. 